\title{
Exhaust Energy Recovery with Variable Geometry Turbine to Reduce Fuel Consumption for Microcars
}

Fernando Ortenzi and Antonino Genovese ENEA

Martina Carrazza, Franco Rispoli, and Paolo Venturini La Sapienza University of Rome

Citation: Ortenzi, F., Genovese, A., Carrazza, M., Rispoli, F. et al., "Exhaust Energy Recovery with Variable Geometry Turbine to Reduce Fuel Consumption for Microcars," SAE Technical Paper 2018-01-1825, 2018, doi:10.4271/2018-01-1825.

\section{Abstract}

he objective proposed by EU to reduce by about $4 \% /$ year $\mathrm{CO}_{2}$ emission of internal combustion engines for the next years up to 2030, requires to increase the engine efficiency and accordingly improving the technology. In this framework, hybrid powertrains can have the possibility of a deep market penetration since they may recover energy during brake, allow the engine to operate in better efficiency conditions and with less transients, Moreover, they can recover a large amount of energy lost through the exhaust and use it to reduce fuel consumption.

This paper concerns the modification of a conventional two in-line cylinders Diesel engine $\left(440 \mathrm{~cm}^{3}\right)$ adding a variable geometry turbine (VGT) coupled with a generator. The turbine is used to recover exhaust gas energy that otherwise would be lost.
The generator, connected to the turbo shaft, converts mechanical energy into electrical energy and is used to charge the vehicle battery or the auxiliaries. The aim of this work is reducing fuel consumption by replacing the alternator with a kind of electric turbo-compounding system to drive vehicle auxiliaries. If the selected turbine recovers enough energy to power auxiliaries, the alternator, which usually has low efficiency, can be removed. Along these lines, fuel consumption savings can be achieved.

At a later stage, a microcar has been tested on WLTC (Class 1) driving cycle.

The results show fuel consumption reduction of 6 to $9 \%$, depending on VGT size. Indeed, four different VGT sizes have been analyzed to choose the optimal configuration that reflects a compromise between energy recovery and fuel consumption reductions.

\section{Introduction}

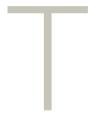

he current strict regulations to reduce $\mathrm{CO}_{2}$ emissions led engine manufacturers in developing new environmentally friendly technologies. To reduce fuel consumption and improve the engine thermal efficiency, in the last decades innovative solutions, such as engine downsizing, turbocharging [1] and turbo-compounding [2], have been implemented. Indeed, the possibility to recover the engine exhaust heat is considered one of the most effective technology available to accommodate greenhouse gas emissions policies.

In internal combustion engine (ICE), approximately only 30 to $40 \%$ of the total thermal energy generated by the combustion is converted into mechanical work [ $\underline{3}$ ]. The remaining part is lost through exhaust gases and engine cooling system. Exhausts temperature can range from 450 to $700{ }^{\circ} \mathrm{C}$, depending on engine size, engine speed and load, therefore their energy content can be relevant.

A turbine can be used to recover a fraction of this energy and drive an electric generator to charge vehicle battery or auxiliaries. In [4] an electric machine, which can be used both as a motor and generator, is connected to a turbocharger shaft in order to power auxiliaries of a heavy-duty engine, thus reducing fuel consumption up to $6 \%$.
Turbo-compound has been investigated for several years and used in different applications with the purpose of increasing engine efficiency. Mechanical turbo-compound, which consists in a turbine connected to engine crankshaft, has never had a widespread diffusion due to the cost and complexity of the system []ㅡ. Electric turbo-compound, on the contrary, has proven to have more advantages than the mechanical one thanks to a mechanical gears removal and a better output flexibility $[\underline{6}, \underline{7}]$.

In this paper only a variable geometry turbine (VGT), coupled to an electric generator, is added to a smalldisplacement Diesel engine. No compressor has been added to raise the inlet fluid density and boost the air inside the cylinders. In this way, the power generated by the VGT, which is proportional to exhaust gases flow rate and temperature, drives only the electric generator, which can charge straight the auxiliaries or the battery. As a result, if an efficient VGT design is realized, the alternator, which usually has a low efficiency about 50-60\% [] ], can be removed.

VGT technology usually is applied in turbocharging system to solve the problem of turbo-lag, which consists in a delay in turbine reaction time during acceleration at low engine speed [9]. Indeed, at low rpm, fixing the turbine geometry, the exhaust flow might be insufficient to satisfy the 
increased load request. VGT application is a suitable way to deal with this issue since decreasing turbine aspect ratio (AR), the velocity of the exhausts increases, and the turbine rotor can gain a greater amount of kinetic energy. Indeed, by changing turbine inlet nozzles angles, the effective area through which the gases flow, and the angle at which the flow impacts the blades, are altered. AR is defined as the ratio between the volute cross sectional area and the distance from the volute geometric center to the cross-sectional area center [10], and VGT uses different mechanical systems to modify this parameter. Such adjustments are not allowed in a fixed geometry turbine, which has a constant AR for all engine operating conditions. Along these lines, VGT modifies nozzle positions to achieve optimal performance across the whole speed engine range.

In this paper, an in-house code (EngineSim), which simulates the thermodynamics and gas dynamics of internal combustion engines [11], is used to analyze the engine behavior (with and without the VGT addition) and extract engine maps. Then, through the engine maps, it has been possible to simulate the performances and fuel consumptions of a microcar on WLTC (Class1) driving cycle, making a comparison between four different VGT sizes.

Turbine maps were obtained through an extrapolation method and using scale factors.

\section{Engine and Vehicle Details}

\section{Engine}

In this study, a four-stroke Lombardini LDW 442 CRS Diesel engine, has been analyzed. Its main characteristics are reported in Table 1.

To avoid excessive smoke at the exhaust, the equivalence ratio shall not exceed the value of 0.6 without adopting any device to reduce the emissions.

Temperatures relative to combustion chamber, piston and cylinders walls are assumed equal to $300,250,150{ }^{\circ} \mathrm{C}$, respectively, while environmental conditions are set as standard (101325 $\mathrm{Pa}$ and $293.15 \mathrm{~K}$ ).

To implement numerical simulations, geometrical data, such as intake and exhaust manifolds sizes, are also necessary. They are reported in Figure 1.

This configuration refers to the original engine without the insertion of the turbine.

TABLE 1 Lombardini LDW 442 CRS main characteristics.

\begin{tabular}{|l|l|}
\hline Displaced volume & $440 \mathrm{cc}$ \\
\hline Bore & $68 \mathrm{~mm}$ \\
Stroke & $60.6 \mathrm{~mm}$ \\
\hline Number of cylinders & 2 in-line \\
\hline Number of intake valves & 2 \\
Number of exhaust valves & 2 \\
Compression ratio & $20: 1$ \\
\hline Injection system & Electronically-controlled direct \\
& injection (Common Rail)
\end{tabular}

FIGURE 1 Lombardini LDW 442 CRS's intake and exhaust manifolds geometry (units: $\mathrm{mm}$ ).

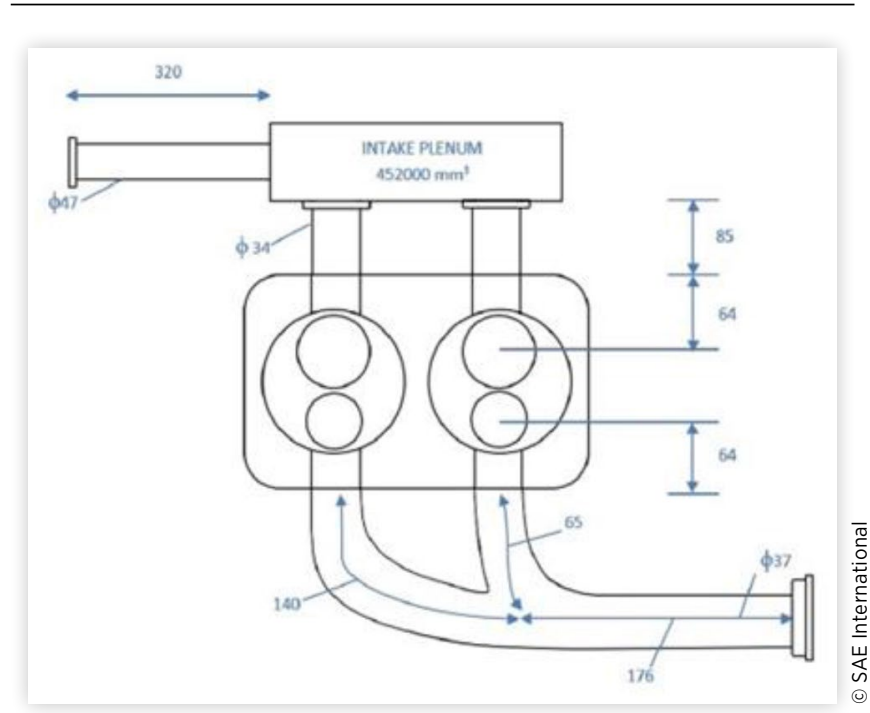

At a later stage, considering the above-mentioned measurements, a fitted VGT has been chosen and added downstream of the exhaust duct.

Since this engine has a small displacement, it is suitable for microcars or A.T.V (All Terrain Vehicles).

\section{Vehicle}

Figure 2 shows the electric turbo-compounding configuration analyzed in this paper. Exhaust gases expand in the VGT, which absorbs their energy content and transmits mechanical energy to a rotating shaft. A VGT driven generator transforms mechanical energy into electric energy, which can be used to supply battery and auxiliaries' energy request. Since the power needed by the electric units is given by VGT, the alternator can be removed and, therefore, the whole power generated by the engine is used to the vehicle drive-train.

For these reasons, it's mandatory to know the energy required to drive various auxiliaries such as lighting, windscreen wiper or air conditioning. Some tests have been carried out on a microcar, Ligier X-TOO, to evaluate auxiliaries' amperage and the results are reported in Table 2.

Assuming a voltage of $12 \mathrm{~V}$, the average power required by auxiliaries can be considered approximately about 200-250 W, depending on applications.

Definition of microcar can be different country-bycountry; here we consider a quadricycle for passenger transport. European directives during the years have

FIGURE 2 Electric turbo-compounding schematic layout.

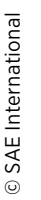

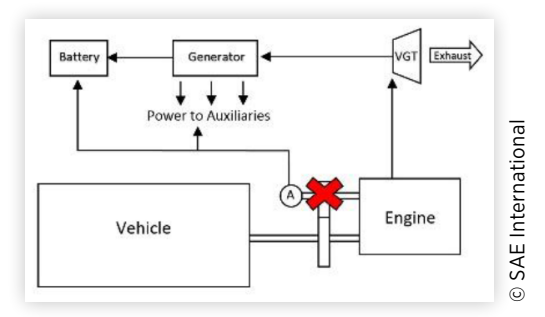

(c) 2018 SAE International. All Rights Reserved. 
TABLE 2 Ligier X-TOO auxiliaries' amperage.

\begin{tabular}{|c|c|}
\hline Auxiliary & Amperage (A) \\
\hline Fan & 8.5 \\
\hline Windscreen wiper & 10 \\
\hline Main-beam headlamps & 10.5 \\
\hline Dipped-beam headlamps & 9.3 \\
\hline
\end{tabular}

TABLE 3 Characteristics and limitations of light and heavy quadricycles imposed by Framework Directive 2002/24/ EC [12].

\begin{tabular}{|c|c|c|}
\hline & Light quadricycle & Heavy quadricycle \\
\hline Unladen mass & $\leq 350 \mathrm{~kg}$ & $\leq 400 \mathrm{~kg}$ \\
\hline Max design speed & $\leq 45 \mathrm{~km} / \mathrm{h}$ & - \\
\hline Max power output & $\leq 4 \mathrm{~kW}$ & $\leq 15 \mathrm{~kW}$ \\
\hline
\end{tabular}

established common framework for quadricycles regulating manufacturing standards and imposing limitations in terms of weight, speed and power $[\underline{12}, \underline{13}]$. The same directives made a distinction between light (L6e) and heavy quadricycles (L7e), whose characteristics and limitations are reported in table 3.

According to the characteristics of the tested engine, a heavy quadricycle was chosen to be studied on WLTC (Class 1) driving cycle.

\section{Turbine Model}

In zero- and one-dimensional simulation codes, to predict turbine behavior, maps related to mass flow rate and efficiency are necessary. Since only a narrow range of turbine experimental data is provided by manufacturers, an extrapolation method must be performed to get an estimate of unknown information.

\section{Extrapolation of VGT Mass Flow Map}

Several empirical and semi- empirical models have been proposed by some authors for the extension of the mass flow map. Watson and Janota in [14] represent a radial fixed geometry turbine as a nozzle placed at exhaust manifold exit, in order to emulate the pressure drop across the turbine. This method was further improved by Payri et al. [15], considering a variable equivalent nozzle flow area for different operating conditions. Other approaches $[\underline{16}, \underline{17}]$ are based on two ideal nozzles in series separated by a chamber having the same volume of the turbine. As shown in Figure 3 , first nozzle represents the turbine stator, in which the first expansion takes place, while the second nozzle corresponds to the turbine rotor.

In [16] it is also assumed that the mass flow through each nozzle (stator and rotor) is the same and is given by Eq. (1).

$\dot{m} \frac{\sqrt{T_{\text {in } 0}}}{P_{\text {in } 0}}=A_{\text {eff }}(V G T, R p m) \cdot \sqrt{\frac{\gamma}{R}}\left(\frac{P_{\text {out }}}{P_{\text {in } 0}}\right)^{\frac{1}{\gamma}} \sqrt{\frac{2}{\gamma-1}\left[1-\left(\frac{P_{\text {out }}}{P_{\text {in } 0}}\right)^{\frac{\gamma-1}{\gamma}}\right]}$
FIGURE 3 Geometry diagram of the turbine model [16].

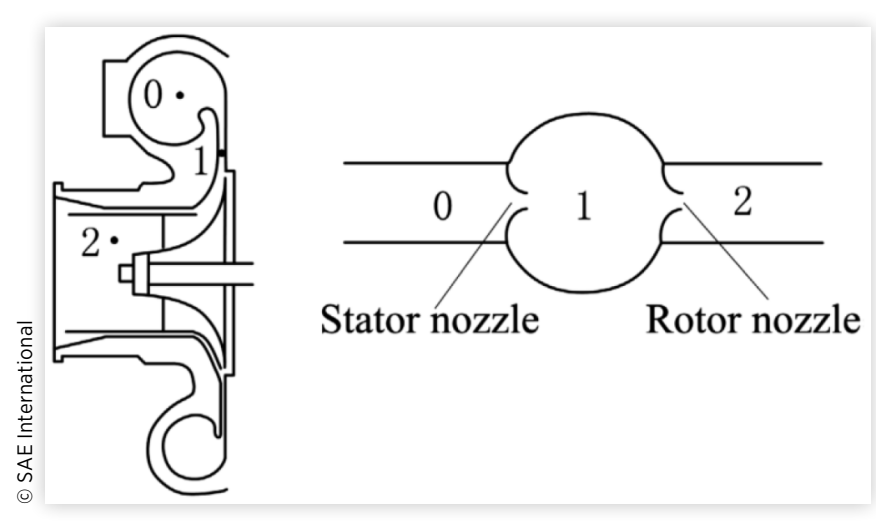

The same mass flow passes through the turbine. $A_{\text {eff }}$ is the equivalent nozzle effective area, and in and out subscripts refer to the inlet and outlet conditions respectively. The effective stator area in function of turbine Rpm and VGT opening value. A further hypothesis of this model is that the pressure drop across the rotor and stator is the same. Indeed, in radial fixed geometry turbine it is common practice assuming $\mathrm{R}=0.5$, where $\mathrm{R}$ is the reaction degree which represents a measure of how much expansion occurs in the rotor compared to the total [18]. Hence, imposing $R=0.5$, half expansion is in the stator, and the other half is in the rotor; by calculating this value, it is possible to evaluate $A_{\text {eff }}$.

Eriksson [19] suggests an expression for the expansion partition:

$$
\Pi_{t}=\underbrace{\sqrt{\Pi_{t}}}_{\text {stator }} \cdot \underbrace{\sqrt{\Pi_{t}}}_{\text {rotor }}
$$

In VGT characterized by shifting stator guide blades position, the hypothesis of $\mathrm{R}=0.5$ is no longer viable at every operating condition.

In this paper, the two nozzles model to replace stator and rotor turbine has been used, but expansion distribution has been modified respect to the previously mentioned methods:

$$
\Pi_{t}=\underbrace{\prod_{t}^{x(V G T)}}_{\text {stator }} \cdot \underbrace{\Pi_{t}^{1-x(V G T)}}_{\text {rotor }}
$$

where $x$ is a parameter representing the fraction of expansion ratio in the corresponding nozzle. The reaction degree was assumed to be variable depending on VGT opening and used as calibration constant.

An algorithm was developed to search, at every operating condition, $x$ value which minimizes the RMSE between experimental data, supplied by manufacturers through turbine maps, and modelled data (Figure 4).

\section{Extrapolation of VGT Efficiency Map}

The extending efficiency map method used in this work is expressed in $[\underline{19}, \underline{20}]$, in which a simple form is applied:

$\eta_{t}=\eta_{t, \max }(V G T, R p m) \cdot\left(1-c(V G T) \cdot\left(1-B S R_{\text {norm }}\right)^{2}\right)$ if $B S R_{\text {norm }}>1$ 
FIGURE 4 Extrapolation of the expansion ratio of the turbine in function of corrected mass flow for VGT opening value of 0.8 (RMSE $=3.41 \mathrm{E}-8$, Correlation $=0.99968)$.

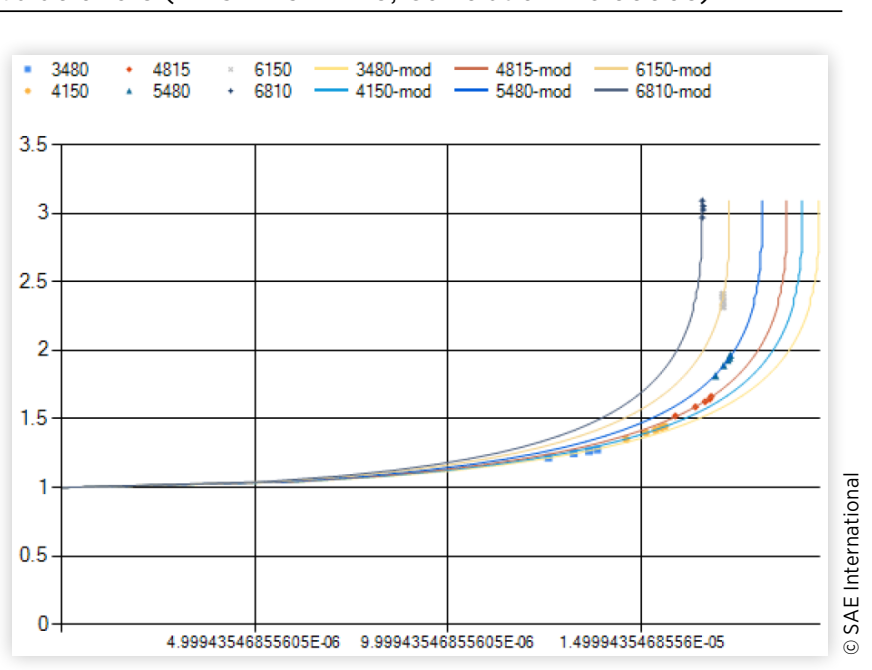

$\eta_{t}=\eta_{t, \max }(V G T, R p m) \cdot\left(1-\left(1-B S R_{n o r m}\right)^{b(V G T, R p m)}\right)$ if $B S R_{n o r m}<1$

where BSR is defined as:

$$
B S R=\frac{\omega_{t} r_{t}}{\sqrt{2 c_{p} T_{\text {in } 0}\left(1-\Pi_{t}^{\frac{\gamma-1}{\gamma}}\right)}}
$$

And $B S R_{n o r m}$ is the ratio between BSR and its maximum value at a fixed turbine Rpm.

\section{Turbine Map Scaling}

VGT maps have been taken from the commercial software LMS AMESim. Table 4 summarizes the main turbine characteristics.

For geometrically similar turbines, existing maps can be scaled to be applied to different turbines simulations.

Considering the ratio of turbine wheel diameters as scaling factor, the characteristic parameters have been changed as follows [리:

$$
\begin{gathered}
\dot{m} \frac{\sqrt{T_{\text {in }}}}{P_{\text {in, new }}} \approx \frac{d_{\text {new }}^{2}}{d_{\text {org }}^{2}} \dot{m} \frac{\sqrt{T_{\text {in }}}}{P_{\text {in, org }}} \\
n_{t, \text { new }} \approx \frac{d_{\text {org }}}{d_{\text {new }}} n_{t, \text { org }} \\
\prod_{t, \text { new }} \approx \prod_{t, \text { org }} \\
\eta_{t, \text { new }} \approx \eta_{t, \text { org }}
\end{gathered}
$$

TABLE 4 VGT characteristics.

\begin{tabular}{ll} 
Wheel Diameter & $35 \mathrm{~mm}$ \\
\hline Exit Diameter & $30 \mathrm{~mm}$ \\
\hline Hub Diameter & $9 \mathrm{~mm}$
\end{tabular}

(c) SAE International

TABLE 5 VGT scale factor.

\section{VGT name}

VGT 1

VGT 2

VGT 3

VGT 4

In this study, four distinct scaled maps were created from the available VGT data and, therefore, four variable geometry turbines have been analyzed with the purpose to compare achievements in terms of energy recovery and fuel consumption savings.

\section{Results and Discussions}

In the present work, an in-house one-dimensional code (EngineSim) has been used to simulate the thermodynamics and gas dynamics of the engine [11]. The main technical features of the above-mentioned mono-dimensional code are:

- “Two-zone” combustion model and Watson model;

- Second order model "Two Step Lax-Wendroff”, together with FCT flux limiter, to calculate one-dimensional gas dynamics within engine manifolds $[\underline{22}, \underline{23}]$.

- First order method of characteristics for pipe boundaries $[\underline{22}, \underline{23}, \underline{24}]$.

- Perfect mixing during the overlap period of the valves (scavenging).

A complete explanation of the implemented code is reported in $[\underline{11}, \underline{25}]$.

In the first step of the analysis, simulations of engine at full and partial loads were performed on conventional and turbo-compounding system in order to obtain engine maps, required for driving cycle analysis, at a later stage.

Some approximations have been assumed to simplify the problem:

- Efficiency electric generator equal to 0.95 .

- In the conventional engine, constant efficiency alternator in whole operating range and equal to 0.50 .

- All the energy recovered by VGT in the turbo-compounding configuration is used for auxiliaries power supply.

To implement partial load simulation, different strategies have been adopted depending on the configuration. In conventional engine, partial load tests have been carried out reducing the amount of fuel and, therefore, decreasing the equivalent ratio. Whereas in turbo-compounding system, the aim has been initially achieved closing the stator vanes, and reducing the equivalent ratio thereafter.

A preliminary test was performed at $2000 \mathrm{rpm}$, when the engine reaches high torque, to get an overview of the energy recovered by the different turbines.

Figure 5 shows the amount of energy produced by each turbine in function of engine power. It can be seen that the 
FIGURE 5 Power recovered by different VGT as a function of engine power and compared with fixed geometry turbine.

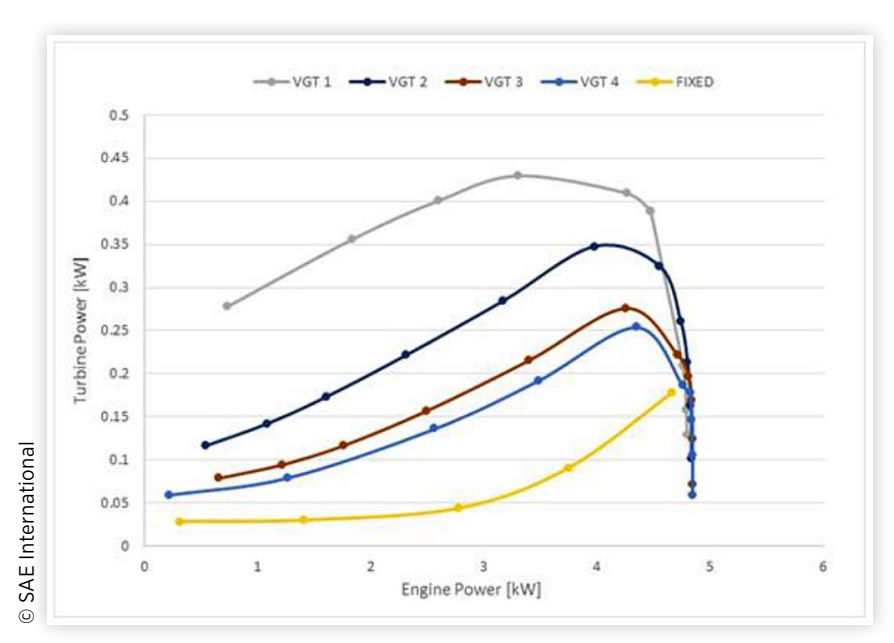

smaller the turbine in size, the more can be recovered in terms of energy. In the figure a comparison with a fixed geometry turbine (FIXED in figure), is reported in order to highlight the advantages of VGT application. The size of the fixed geometry turbine was chosen similar to VGT 4. However, the addition of the turbine downstream of exhaust duct, acts as a narrowing and induces an increase of backpressure on the engine.

This result can be observed in Figure 6 in which the conventional engine power, called "Conventional simulated data", has been compared to the engine power of the turbocompounding system, "TurboVGT 3 simulated data", equipped with VGT 3. Higher exhaust backpressure causes a drop in engine performance, which corresponds to higher fuel consumption for the same amount of brake power delivered. Moreover, the figure shows the comparison between conventional engine experimental data, measured on the test bench, and conventional engine simulated data obtained using the software. It exhibits a good correlation with the measured data.

The study performed so far has been allowed to get engine maps, needed for the driving cycle tests.

WLTC (Class 1) driving cycle, characterized by low engine load and low vehicle speed (maximum speed of $64.4 \mathrm{~km} / \mathrm{h}$ ),

\section{FIGURE 6 Maximum power curves (full load): comparison} among "Conventional simulated data", "Conventional experimental data" and "TurboVGT 3 simulated data".

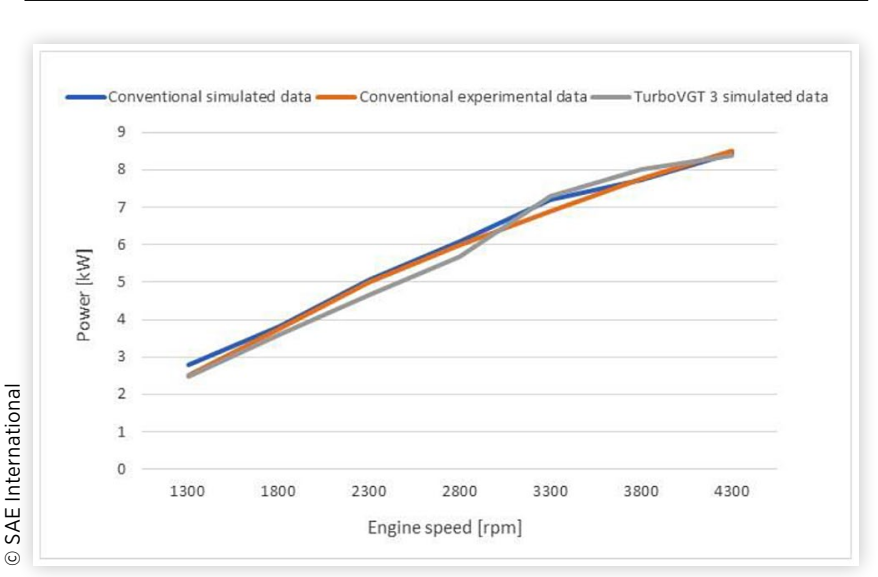

(c) 2018 SAE International. All Rights Reserved. has been simulated. Information regarding the instantaneous power, required to move the quadricycle, is needed in order to compute the fuel consumption on the driving cycle. This power can be computed taking into the account four terms: tire friction, aerodynamic resistance, road slope and inertial factor [26]. Furthermore, to perform the simulation, the value of instantaneous power produced by the VGT has to be provided, moving from engine maps implementation. Indeed, turbine energy recovery is strictly related to exhaust gases temperature and, therefore, to engine load and speed. Obviously, for the conventional engine case, the power required by the turbine has been considered null and the energy wasted by the alternator has been taken into the account.

Along these lines, it has been possible to associate instantaneous power recovered by the turbine with the instantaneous engine power required to move the vehicle during driving cycle simulation.

The analysis has been carried out for the four distinct VGTs and the average power recovery values (AVR) are reported in Table 6.

As already said, smaller size VGTs, have the possibility to recover more energy.

Fuel consumption of the conventional configuration has been evaluated according to the alternator efficiency and to the hypothesis that energy needed by the auxiliaries is the same of those recovered by each VGT.

Four different tests (one for each turbine considered) have been carried out and for each test a different energy value required by auxiliaries has been chosen, depending on the kind of turbine used. In this way, also for conventional system, distinct fuel consumption results have been obtained, depending on the energy units request.

Figure 7 shows conventional and turbo-compounding fuel consumption trends during WLTC (Class 1) driving cycle. In this figure, only the turbo-compounding configuration equipped with VGT 3 has been reported (called

TABLE 6 Turbine average power recovery within the whole driving cycle.

\begin{tabular}{|l|l|l|l|l|}
\hline Driving cycle & $\begin{array}{l}\text { VGT 1 } \\
\text { AVR (W) }\end{array}$ & $\begin{array}{l}\text { VGT 2 } \\
\text { AVR (W) }\end{array}$ & $\begin{array}{l}\text { VGT 3 } \\
\text { AVR (W) }\end{array}$ & $\begin{array}{l}\text { VGT 4 } \\
\text { AVR (W) }\end{array}$ \\
\hline WLTC (Class 1) & 400 & 340 & 260 & 230 \\
\hline
\end{tabular}

FIGURE 7 Fuel consumptions during WLTC driving cycle.

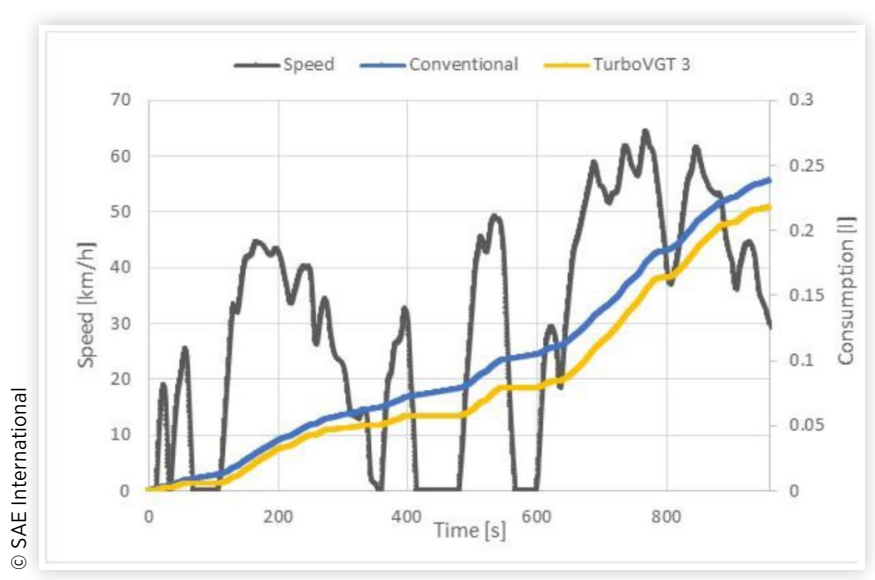


FIGURE 8 Fuel consumption in terms of $\mathrm{l} / 100 \mathrm{~km}$ during WLTC (Class 1) driving cycle.

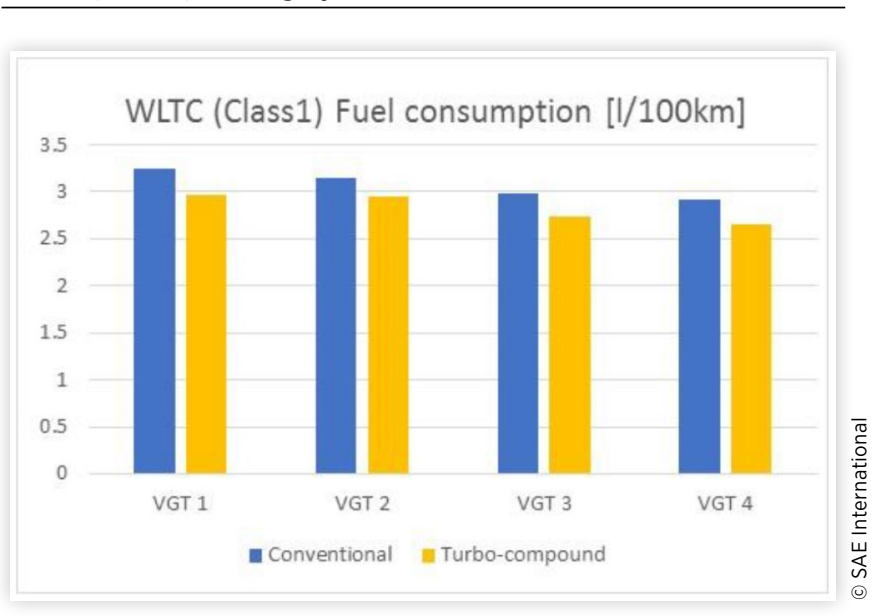

TABLE 7 Fuel consumption savings.

\begin{tabular}{|c|c|c|c|c|}
\hline $\begin{array}{l}\text { Driving } \\
\text { cycle }\end{array}$ & $\begin{array}{l}\% \text { Fuel } \\
\text { Savings } \\
\text { VGT } 1\end{array}$ & $\begin{array}{l}\% \text { Fuel } \\
\text { savings } \\
\text { VGT } 2\end{array}$ & $\begin{array}{l}\% \text { Fuel } \\
\text { savings } \\
\text { VGT } 3\end{array}$ & $\begin{array}{l}\% \text { Fuel } \\
\text { savings } \\
\text { VGT } 4\end{array}$ \\
\hline $\begin{array}{l}\text { WLTC } \\
\text { (Class 1) }\end{array}$ & $8 \%$ & $6 \%$ & $8.5 \%$ & $9 \%$ \\
\hline
\end{tabular}

"TurboVGT3"), whereas the other results have been summarized in Figure 8. The fuel consumption reduction depends on the experimental settings and the selected VGT. As Table 7 shows, they are about 6 to $9 \%$ and the maximum fuel saving is reached using VGT 4.

Considering the results summarized in Table 6, all VGT average power recovery values (AVR) are equal or greater than those required to drive vehicle auxiliaries. Thus, it is conceivable that once VGT has recovered enough energy to power auxiliaries and charge the battery, it can be opened rotating stator vanes. Along these lines the backpressure decreases and engine performance improves, reducing fuel consumption.

Following this approach and considering $200 \mathrm{~W}$ as the power required by electric units, simulations have been carried out on WLTC driving cycle for the four selected VGTs. The results have been reported in Figure 9 and Table 8 .

\section{FIGURE 9 Fuel consumption in terms of $\mathrm{I} / 100 \mathrm{~km}$ during} WLTC (Class 1) driving cycle recovering $200 \mathrm{~W}$ to drive auxiliaries.

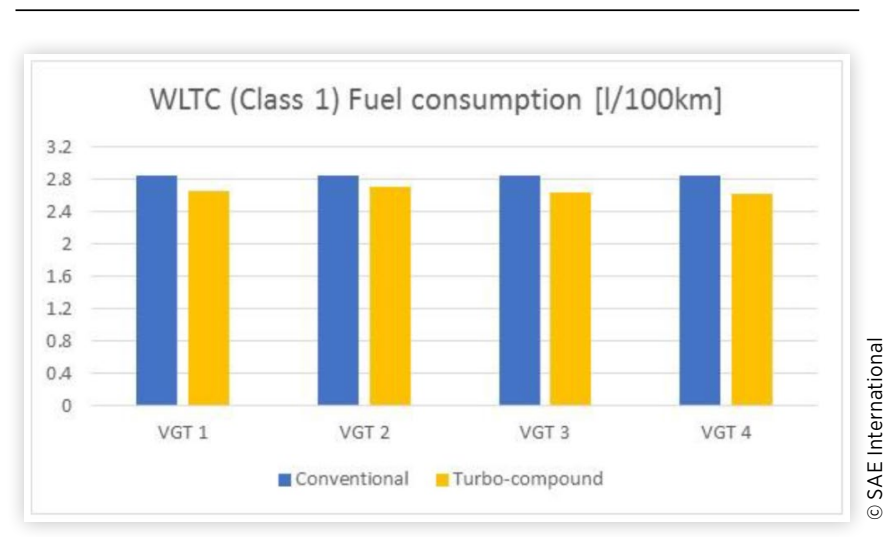

TABLE 8 Fuel consumption savings recovering 200 W to drive auxiliaries.

\begin{tabular}{|c|c|c|c|c|}
\hline $\begin{array}{l}\text { Driving } \\
\text { cycle }\end{array}$ & $\begin{array}{l}\% \text { Fuel } \\
\text { savings } \\
\text { VGT } 1\end{array}$ & $\begin{array}{l}\% \text { Fuel } \\
\text { savings } \\
\text { VGT } 2\end{array}$ & $\begin{array}{l}\% \text { Fuel } \\
\text { savings } \\
\text { VGT } 3\end{array}$ & $\begin{array}{l}\% \text { Fuel } \\
\text { savings } \\
\text { VGT } 4\end{array}$ \\
\hline $\begin{array}{l}\text { WLTC } \\
\text { (Class 1) }\end{array}$ & $6.5 \%$ & $4.8 \%$ & $7.2 \%$ & $8 \%$ \\
\hline
\end{tabular}

\section{FIGURE 10 Power supplied to auxiliaries in function of electric generator efficiency.}

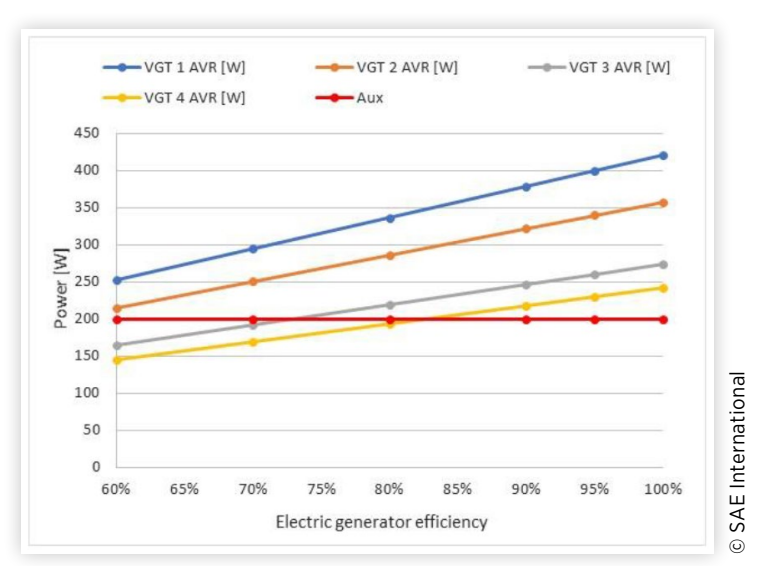

The performed analysis has proved that fuel consumption reductions can be achieved replacing alternator with a VGT coupled to an electric generator. However it is necessary to evaluate how electric generator efficiency is related to fuel consumption savings.

Generator efficiency affects the power supplied to the auxiliaries as it is shown in Figure 10.

In Figure 11, it is reported the fuel consumption savings, depending on electric generator efficiency, reached during WLTC driving cycle by the turbo-compounding configuration with VGT 3.

Improving alternator efficiency, fuel consumption reductions increase, but advantages can be obtained with this

FIGURE 11 Fuel consumption savings in function of electric generator efficiency for VGT 3 turbo-compounding configuration.

\section{WLTC (Class 1) \% Fuel consumption savings}

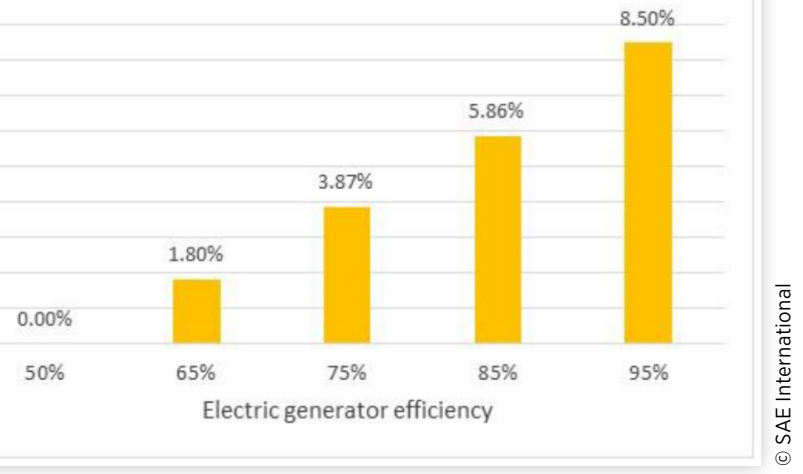

(c) 2018 SAE International. All Rights Reserved. 
turbo-compounding configuration up to $65 \%$ of generator efficiency. It is necessary to consider that alternator belt efficiency usually is around $85 \%$ and therefore a comparison between an alternator with an efficiency of $50 \%$ and a generator of $65 \%$ is proper.

\section{Conclusions}

In the present work, a modification of a small-displacement Diesel engine, adding a VGT coupled with an electric generator, has been analyzed through a one-dimensional engine simulation.

It has been proved that driving vehicle auxiliaries through exhaust gases energy, recovered by VGT, and removing alternator, fuel consumption savings of 6 to $9 \%$ can be achieved with respect to the conventional configuration. Moreover, considering auxiliaries average power constant to $200 \mathrm{~W}$ and rotating stator vanes for a VGT full-opening once it has recovered the required energy, fuel consumption reductions of 4.8 to $8 \%$ can be reached.

The advantages of electric turbo-compound, used to charge battery or auxiliaries, are evident and this application can represent an effective solution to reduce fuel consumption and, therefore, $\mathrm{CO}_{2}$ emission accommodating greenhouse gas emissions policies.

\section{Nomenclature}

$A_{\text {eff }}$ - Equivalent nozzle flow area

$A R$ - Aspect ratio

$A V R$ - Turbine average power recovery

BSR - Blade speed ratio

$\boldsymbol{c}_{p}$ - Specific heat capacity at constant pressure

$\boldsymbol{d}$ - Diameter

FCT - Flux Corrected Transport

ICE - Internal combustion engine

$\dot{\boldsymbol{m}}$ - Mass flow rate

$\boldsymbol{n}$ - Number of revolutions

$\boldsymbol{P}$ - Pressure

$\boldsymbol{R}$ - Perfect gas constant

$\mathbf{R}$ - Reaction degree

RMSE - Root Mean Square Error

$r_{t}$ - Rotor radius

$\boldsymbol{T}$ - Temperature

VGT - Variable geometry turbine

\section{Greek symbols}

$\gamma$ - Specific heat ratio

$\boldsymbol{\eta}_{\boldsymbol{t}}$ - Turbine efficiency

$\Pi_{t}$ - Ratio of turbine inlet to outlet pressure

$\omega_{t}$ - Rotor angular velocity

\section{References}

1. Silva, C., Ross, M., and Farias, T., "Analysis and Simulation of "Low-Cost" Strategies to Reduce Fuel Consumption and Emissions in Conventional Gasoline Light-Duty Vehicles," Energy Conversion and Management 50(2):215-222, 2009.

2. Bin Mamat, A.M.I., Martinez-Botas, R.F., Chiong, M.C., Rajoo, S. et al., "Exhaust Gas Energy Recovery via Electric Turbocompounding," Energy Procedia 75:1555-1559, 2015.

3. Jadhao, J.S. and Thombare, D.G., "Review on Exhaust Gas Heat Recovery for I.C. Engine," International Journal of Engineering and Innovative Technology (IJEIT) 2:93-100, 2013.

4. Millo, F., Mallamo, F., Pautasso, E., and Ganio, M.G., "The Potential of Electric Exhaust Gas Turbocharging for HD Diesel Engines," SAE Technical Paper 2006-01-0437, 2006, doi:10.4271/2006-01-0437.

5. Jye, A.E.T.S., Pesyridis, A., and Rajoo, S., "Effects of Mechanical Turbo Compounding on a Turbocharged Diesel Engine," SAE Technical Paper 2013-01-0103, 2013, doi:10.4271/2013-01-0103.

6. Wei, W., Zhuge, W., Zhang, Y., and He, Y., "Comparative Study on Electric Turbo-Compounding Systems for Gasoline Engine Exhaust Energy Recovery," Proceedings of ASME Turbo Expo 2010: Power for Land, Sea and Air, Glasgow, UK, June 14-18, 2010.

7. Algrain, M. and Hopmann, U., "Diesel Engine Waste Heat Recovery Utilizing Electric Turbocompound Technology, Proceedings of 2003 DEER Conference, Newport, Rhode Island, Aug 25-28, 2003.

8. Perreault, D.J. and Caliskan, V., "Automotive Power Generation Control," IEEE Transactions on Power Electronics 19(3):618-630, 2004.

9. Watson, N. and Banisoleiman, K., "Performance of the Highly Rated Diesel Engine with a Variable Geometry Turbocharger," ImechE Conference on Turbocharging and Turbochargers, C121/86, London, 1986.

10. Feneley, A.J., Pesiridis, A., and Andwari, A.M., "Variable Geometry Turbocharger Technologies for Exhaust Energy Recovery and Boosting - A Review," Renewable and Sustainable Energy Reviews 71:959-975, 2017.

11. Ortenzi, F. and Vesco, E., "An Improved Multi-Pipe Junction Model for Engine Thermodynamic and Gas Dynamic Simulations," SAE Technical Paper 2013-24-0069, 2013, doi:10.4271/2013-24-0069.

12. "Directive 2002/24/EC of the European Parliament and of the council of 18 March 2002 relating to the type-approval of two or three-wheel motor vehicles and repealing Council Directive 92/61/EEC". Available at: eur-lex.europa.eu.

13. "EQUAL's Answer to the European Commission Non-Paper MCWG Meeting." Available at: circabc.europa.eu.

14. Watson, N. and Janota, M.S., Turbocharging the Internal Combustion Engine (London: MacMillan Publishers Ltd, 1982).

15. Payri, F., Serrano, J.R., Fajardo, P., Reyes-Belmonte, M.A., and Gozalbo-Belles, R., "A Physically Based Methodology to Extrapolate Performance Maps of Radial Turbines," Energy Conversion and Management 55:149-163, 2012. 
16. Payri, F., Benajes, J., and Reyes, M., "Modelling of Supercharger Turbines in Internal Combustion Engines," International Journal of Mechanical Sciences 38(8):853869, 1996.

17. Serrano, J.R., Arnau, F.J., Dolz, V., Tiseira, A., and Cervelló, C., "A Model of Turbocharger Radial Turbines Appropriate to Be Used in Zero- and One-Dimensional Gas Dynamics Codes for Internal Combustion Engines Modelling," Energy Conversion and Management 49:3729-3745, 2008.

18. Zhu, S., Deng, K., and Liu, S., "Modeling and Extrapolating Mass Flow Characteristics of a Radial Turbocharger Turbine," Energy 87:628-637, 2015.

19. Eriksson, L., "Modeling and Control of Turbocharged SI and DI Engines," Oil \& Gas Science and Technology - Rev. IFP 62(4):523-538, 2007.

20. Cavina, N., Borelli, A., Calogero, L., Cevolani, R., and Poggio, L., "Turbocharger Control-Oriented Modeling: Twin-Entry Turbine Issues and Possible Solutions," SAE Technical Paper 2015-24-2427, 2015, doi:10.4271/201524-2427.
21. Kaufmann, A., "Using Turbocharger Maps in Gas Exchange Simulation and Engine Control Units," Forschung auf dem Gebiete des Ingenieurwesens 78(1-2):45-57, 2014.

22. Benson, R.S.. In: Horlock J.H., Winterbone D.E., editors. The Thermodynamics and Gas Dynamics of Internal-Combustion Engines. (Clarendon Press, 1982).

23. Ll, G. and García, J.A., "About the TVD Property for the Flux-Corrected Transport Techniques," Computational Mechanics 30(4):281-285, 2002.

24. Winterbone, D.E. and Pearson, R.J., Theory of Engine Manifold Design (Professional Engineering Pub, 2000).

25. Ortenzi, F., "La Simulazione Dei Motori A 4 Tempi: Le Caratteristiche Di Un Apposito Software", Mototecnica Anno 19(N²), 2005 (in Italian).

26. Alessandrini, A., Filippi, F., Orecchini, F., and Ortenzi, F., "A New Method for Collecting Vehicle Behaviour in Daily Use for Energy and Environmental Analysis," Proceedings of the Institution of Mechanical Engineers, Part D: Journal of Automobile Engineering 220(11):1527-1537, 2006. 